\title{
O LUGAR DA AMÉRICA LATINA NAS RELAÇÕES SUL-SUL: O PAPEL DA COMUNIDADE DE ESTADOS LATINO-AMERICANOS E CARIBENHOS (CELAC) NA INTEGRAÇÃO LATINO-AMERICANA
}

\author{
THE PLACE OF LATIN AMERICA IN SOUTH-SOUTH RELATIONS : THE COMMUNITY \\ ROLE OF UNITED LATIN AMERICAN AND CARIBBEAN (ECLAC ) IN LATIN AMERICAN \\ INTEGRATION
}

Francisco Denes Pereiral

Universidade de São Paulo, São Paulo, Brasil.

\begin{abstract}
Resumo: O objetivo principal do desse artigo é analisar a criação da CELAC e seu papel no processo de integração latino-americano atual. Atenta-se a compreender a construção do diálogo e da concertação política entre os países latino-americanos e qual o balanço dos resultados dessas iniciativas. Aprofunda-se o estudo sobre a criação da CELAC, sua conformação institucional, assim como seus principais desafios frente a existência da Organização dos Estados Americanos (OEA) e sua efetividade.
\end{abstract}

Palavras-chaves: América Latina e Caribe; Integração Regional; Regionalismo.

\begin{abstract}
The main objective of this paper is to analyze the creation of CELAC and its role in the current Latin American integration. Attentive to understand the construction of dialogue and political cooperation among Latin American countries and which sum up the results of these initiatives. Deepens the study on the creation of CELAC, its institutional conformation, as well as its main challenges facing the existence of the Organization of American States (OAS) and its effectiveness.
\end{abstract}

Keywords : Latin America and the Caribbean; Regional Integration; Regionalism.

\section{INTRODUÇÃO}

A crise no sistema financeiro mundial, com seu ápice no ano de 2008, mostrou a fragilidade do multilateralismo econômico e político atual e também do unilateralismo estadunidense. A maior presença de potências emergentes com grande peso militar e econômico no sistema internacional como Brasil, China e Rússia e a emergência de temas globais relevantes como as crises energéticas, alimentarias e climáticas provocam a comunidade internacional para que impulsionem agendas para tratar de tais problemáticas de forma conjunta e estratégica.

Nesse contexto, a América Latina tem a necessidade de construir um projeto político estratégico que lhe permita ter uma posição comum e efetiva em torno dos temas prioritários da nova agenda internacional. A construção deste projeto constitui-se em um desafio para o continente, já que está inserida em uma diversidade de temas de cunho global que faz com

\footnotetext{
${ }^{1}$ Mestrando no PROLAM/USP; Membro do Núcleo de Estudos e Pesquisas de Política Internacional, Estudos Internacionais e Políticas Comparadas (NESPI-CNPq). email<francisco.prolam@usp.br>.
} 
que os atores estatais e não estatais tenham que elaborar respostas estratégicas e coordenadas a estas novas agendas que envolvem uma diversidade maior de temas culturais, econômicos, financeiros, segurança, cultural, desigualdade social, segurança alimentar, defesa regional, combate a corrupção e direitos humanos que moldam a todo o momento o cenário internacional e, assim, o relacionamento entre os países. Para pensar estes processos e suas consequências à região e aos Estados nacionais, requer-se uma maior concertação política e associação para uma maior cooperação regional.

As iniciativas de integração em curso na região como o Mercado Comum do Sul (MERCOSUL), a Comunidade Andina (CAN), Aliança do Pacífico, União de Nações SulAmericana (UNASUL), a Aliança Bolivariana dos Povos de nossa América (ALBA) e Comunidade Econômica do Caribe (CARICOM) apresentam um caminho a essa concertação. Cada organização surge com características e objetivos diferenciados, mas com desafios comuns. É nesse caminho que os Estados nacionais e suas políticas externas em favor da integração regional convergiam para a criação da Comunidade de Estados Latino-Americanos e Caribenhos (CELAC), a nova organização regional constituída por Estados latinoamericanos, sem a presença dos Estados Unidos e do Canadá nas discussões e deliberações.

A implementação de mais de uma década de políticas neoliberais na maior parte dos países da região, levaram a esses países de graves crises econômicas, sociais e políticas. Os impactos dessa crise foram tão profundos que a década dos 90 foi chamada de "década perdida", pela consequência do impacto econômico e financeiro nas economias latinoamericanas. As graves crises de desvalorização cambial que atingiram o Brasil em 1998 e a Argentina em 2001 foram o reflexo de medidas neoliberais adotadas em anos anteriores.

Nesta direção, Souza (2012) analisa a mudança política que se produziu na região da seguinte maneira:

A onda neoliberal que, num primeiro momento, contribuiu para enquadrar o processo de integração latino-americana nos marcos do livre comércio e do regionalismo aberto, terminou favorecendo a busca de caminhos mais profundos de integração, ao criar as condições (crises econômicas e sociais recorrentes) que levaram à constituição de governos progressistas na região. $\mathrm{O}$ momento decisivo, que abriu um novo processo de integração regional, foi o fracasso do projeto estadunidense de criar a Área de Livre Comércio das Américas (ALCA). Tratava-se da terceira grande estratégia do governo dos EUA na busca de superação da crise estrutural (SOUZA, 2012, p. 25). 
Diante desse contexto, a emergência de novos regionalismos na América Latina é entendida por esse esgotamento do "regionalismo aberto", caracterizado por sua primazia na agenda de liberalização comercial e uma ótica economicista (SANAHUJA, 2010). Esse fator foi decisivo para que um novo cenário regional fosse construído, que tem a ver com o surgimento de novas alianças políticas e sociais que foram importantes para que novos quadros governistas de origem popular chegassem ao poder; exemplo disso é a chegada à presidência de Lula da Silva no Brasil, de Nestor Kirchner na Argentina, Hugo Chaves na Venezuela, Evo Morales na Bolívia, Rafael Correa no Equador, Tabaré Vásquez no Uruguai e Fernando Lugo no Paraguai.

Esses novos governos passaram a adotar políticas para enfrentar as crises e responder às demandas sociais de suas populações. Essas políticas possibilitaram uma mudança na condução da política externa, da inserção comercial e dos modelos de desenvolvimento dos países latino-americanos, tendo como elemento comum a todos esses governos o "antineoliberalismo" nas políticas econômicas (BERNAL-MEZA, 2012). As linhas do "regionalismo aberto" foram gradualmente sendo abandonadas e substituídas por novos modelos de regionalismo, integração e cooperação que refletem esse novo contexto.

Há uma clara redefinição do regionalismo e da integração latino-americana. Estas mudanças têm, por vezes, enfoques e análises distintas, por vezes contraditórias, mas que em comum carregam prioridades que vão dar corpo ao que chamamos de regionalismo pósneoliberal. De alguma forma, em maior ou menor intensidade, os países abandonaram o modelo neoliberal anterior e colocaram o Estado novamente como ator central no processo de desenvolvimento da nação, aplicando políticas protecionistas e fortalecendo instituições estatais.

As promessas ditadas pela globalização foram vistas como um perigo às economias e às sociedades, assim como a aproximação com os Estados Unidos, sendo que a potência e o conjunto de instituições multilaterais sob sua liderança como FMI e Banco Mundial foram apontados por estes novos governos como responsáveis pela formulação e implementação de políticas de abertura, liberalização, privatizações e desregulação, causas principais da crise na região. É nesse contexto que surge a CELAC.

No presente artigo, procura-se apontar a importância da nova instância como mecanismo fruto deste contexto atual e na maior de coordenação de agendas dos governos da região em temas comuns. O objetivo é analisar a CELAC e qual o seu papel no processo de integração atual dentro do que se chama de regionalismo pós-neoliberal, que se inicia a partir 
da década passada até os dias atuais.

Para apresentar a temática proposta e tentar responder a algumas perguntas sobre a discussão, o artigo será apresentado em duas partes. A primeira dedica-se a realizar um breve recorrido histórico do projeto para criar a CELAC, desde a proposta brasileira na criação de iniciativas de integração no continente até as cúpulas que materializam o projeto e criaram a nova organização latino-americana sem a presença dos Estados Unidos e Canadá. Na segunda parte do trabalho discutimos a potencialidades e limitações da nova organização internacional e quais seus principais desafios para que possa cumprir sua missão e objetivos propostos.

\section{A POLÍTICA EXTERNA BRASILEIRA PARA A AMÉRICA LATINA E CARIBE}

No Governo do presidente Lula da Silva (2003-2010) há uma prioridade da política externa brasileira pela integração regional. Em seu discurso de posse, Lula deixa claro que:

\footnotetext{
A grande prioridade da política externa durante o meu Governo será a construção de uma América do Sul politicamente estável, próspera e unida, com base em ideais democráticos e de justiça social. Para isso é essencial uma ação decidida de revitalização do MERCOSUL, enfraquecido pelas crises de cada um de seus membros e por visões muitas vezes estreitas e egoístas do significado da integração. O MERCOSUL, assim como a integração da América do Sul em seu conjunto é, sobretudo um projeto político (LULA, 2003).
}

Já no primeiro mandato, o presidente já havia visitado todos os países da América Latina, usando da diplomacia presidencial para uma maior aproximação com os vizinhos. Pode-se constatar no discurso do presidente Lula da Silva que há "durante seus dois governos, uma aparente coerência entre a busca de uma maior inserção soberana na globalização, a retomada de um projeto nacional de desenvolvimento e a nova agenda de ativismo estatal" (ROMANO apud MARCHETTI, 2013, p. 215). Desta maneira, observa-se como o governo optou por diversificar suas parcerias sem deixar de reconhecer a importância das relações com as potências, principalmente no que se refere às relações econômicas internacionais.

A política de integração impulsada pelo Brasil constitui-se em uma política de Estado, que se encontra codificada em sua própria Constituição nacional, no artigo $4^{\circ}$, Parágrafo Único: “A República Federativa do Brasil buscará a integração econômica, politica, social e cultural dos povos da América Latina, visando a formação de uma comunidade latinoamericana de nações" (Artigo 4º Parágrafo único - CF 1988). 
Por esse motivo, procurou-se aprofundar ao máximo os processos de integração já existentes, assim como a criação de novas instituições. Para isso, tratou de estabelecer uma série de ações do sentido de aprofundar o processo de integração regional, ações essas que priorizaram o aspecto político da integração. Aqui vale a pena afirmar o papel que jogou o interesse nacional na definição da política externa brasileira com seus vizinhos.

Apesar desse objetivo político brasileiro de uma integração com toda América Latina e Caribe, a "possível e operativa era a da América do Sul” (AMORIM, 2009, p. 19). A aproximação dos países da América Central e Caribe com os Estados Unidos através de tratados de livre comércio (TLCs) e acordos preferenciais dificultavam uma integração maior com esses países. Para o chanceler brasileiro do período, Celso Amorim (2009), havia três níveis de integração possíveis de identificar:

(1) o MERCOSUL, uma união aduaneira, com Parlamento, e já com políticas comuns em muitos aspectos; (2) a América do Sul, que vive um processo de integração bastante forte. Do ponto de vista da política externa e de política internacional, acho que ela tem um papel tão grande, ou talvez maior do que o do Mercosul, porque os grandes temas que existem na região, em geral, transcendem o aspecto do Mercosul; e (3) em um nível um pouco menos cerrado, há o conjunto da América Latina e Caribe, em que se reconhece os diferentes graus de desenvolvimento entre os países (AMORIM, 2009, p. 22)

Em consequência disto vemos a participação do governo na criação de outras iniciativas regionais de integração, como a própria UNASUL, sucessora da Comunidade SulAmericana de Nações (CASA) ${ }^{2}$ criada em 2004, sendo uma proposta efetiva do Brasil na III Cúpula de Presidentes da América do Sul, realizada em Cuzco, Peru. Em suma, a construção dessa nova organização regional representou a consolidação do Estado brasileiro como líder regional, já que houve um consenso na proposta transcrita anteriormente, onde os países se dispuseram a cooperar nos termos estabelecidos na referida reunião.

Devido às assimetrias regionais, o Brasil sempre foi superavitário nas relações comerciais com os vizinhos, o que representa um grande desafio ao projeto de integração regional. Segundo Leite (2010), só em exportações do Brasil para o MERCOSUL, houve um

\footnotetext{
2 A CASA abrangia todos os países da América do Sul em um acordo que visava a harmonização entre dois processos de integração distintos: CAN e Mercosul, além de promover a integração física, econômica e política na sub-região. (AMORIM, 2009, p. 33)
} 
aumento de quatro vezes entre 2002 e 2006, passando de US\$ 3,3 bilhões para US\$ 14 bilhões. Para a América do Sul, entre os anos de 2003 e 2006 as exportações aumentaram de US\$ 10 bilhões para US\$26,6 bilhões.

Em um contexto da ascensão de governos progressistas em grande parte do continente, o Brasil preocupou-se em amenizar os prejuízos provocados por essas assimetrias nas relações econômicas com seus vizinhos. No âmbito do MERCOSUL destaca-se a criação do Fundo de Convergência Estrutural (FOCEM), utilizado, em grande medida, pelas economias do Uruguai e Paraguai. O FOCEM, criado em 2006, já contava com US\$ 100 milhões. Em 2008 esse número subiu para a casa dos US\$ 225 milhões. Acerca das contribuições exigidas para cada país, vemos que só o Brasil já contribui com $70 \%$ do fundo, enquanto que a Argentina (segunda maior economia do bloco) contribui com $27 \%$, Uruguai com $2 \%$ e Paraguai com 1\% (VIZENTINI, 2007, p. 88).

Percebe-se aqui que a contribuição está diretamente relacionada com o tamanho da economia. O Brasil, como a maior do bloco, líder do processo de integração na região, reconhece que, para manter a integração, é necessário compensar os países menores.

O fortalecimento da integração regional na agenda de política externa brasileira nos dois mandatos do Governo Lula foi possível graças a criação de canais de confiança entre o Brasil e seus vizinhos. Através de mecanismos como cúpulas, encontros presidenciais, fóruns de discussão e a criação e o fortalecimento de instituições foram importantes para aproximar os Estados em áreas estratégicas como a infraestrutura, defesa, segurança, sociais sem deixar de privilegiar também os fluxos comerciais, consolidando, assim, espaços de cooperação a longo prazo, que construíram vínculos mais fortes entre o Brasil e países da região. Por reconhecer a importância do país e suas capacidades materiais, a política externa de Lula procurou "[...] assumir o lugar devido como protagonista da mudança na configuração mundial de poder, de forma ativa e criativa [...]" (ROMANO, 2013 apud MARCHETTI, 2013, p. 210).

A inspiração brasileira pela integração latino-americana fez com este realiza-se de forma inédita uma Cúpula dos Países da América Latina e do Caribe reunindo os 33 chefes e chefas de Estado e Governo. Essa foi à concretização de um projeto mais amplo dentro da PEB. Aravena destaca a importancia de tal cúpula:

La realización de esta Cumbre se enmarcó en la búsqueda de una mayor autonomía de América Latina y el Caribe, luego de décadas del olvido por su máximo referente del siglo XX, Estados Unidos, y en un 
contexto en donde surgen nuevos actores globales de peso, entre ellos el mismo Brasil (ARAVENA, 2011, p. 37).

Alguns teóricos vão colocar que a partir de 2001 após os atentados terroristas, a região perde importância na agenda de atuação estadunidense; outras regiões, como o Oriente Médio, passam a ter uma atenção maior devido a chamada Guerra ao Terror. ${ }^{3}$ Outro argumento não excludente é que se entende que a retomada dos processos de integração seria uma forma de combater a dependência:

Novamente, a integração passou a ser vista por diversos países latinoamericanos como uma forma de articulação regional que tem como objetivo ampliar os mecanismos de poder que visam combater a dependência. É por esta razão que os antigos instrumentos de integração estão sendo reformados e novos tem sido criados: Comunidade Sul-Americana de Nações (CASA) depois rebatizado como União das Nações Sul-Americanas (UNASUL), Alternativa Bolivariana para as Américas (ALBA), Petrosul e PetroAmérica, Telesur, Bandesul; refundação do Mercosul, sua ampliação e aprofundamento com propostas de criação de uma moeda única e de um parlamento no bloco; etc ( SOUZA, 2008, p. 15) .

Nesse caminho, a concretização da I Cúpula da América Latina e Caribe sobre Integração e Desenvolvimento (CALC), ocorrida em dezembro de 2008, na Costa do Sauípe, Bahia, teve como objetivo dar respostas latino-americanas a problemas latino-americanos. Como bem colocou o presidente Lula da Silva no discurso de abertura da CALC:

Queremos dar respuestas propias para las aspiraciones de bienestar y prosperidad de nuestros pueblos. Pasados dos siglos desde nuestras independencias, esta es la primera vez que la región une sus voces (...). Esta Cumbre tiene un mensaje simple, pero fundamental: Sólo lograremos superar los retos de laintegración y el desarrollo si asumimos nuestra vocación latinoamericana y caribeña. Debemos hacerlo sin un espíritu de confrontación con nadie. Nuestra unidad debe entenderse como una contribución a un nuevo mundo multipolar y multilateral (DISCURSO PRESIDENCIAL, LULA, 2008, p. 2).

O discurso do presidente Lula deixa evidente que neste momento de conformação da CALC há uma vontade política para dialogar sobre temas de interesse regional frente aos

\footnotetext{
3 Após os atentados de 11 de Setembro, os EUA voltam suas agendas de política externa para o Oriente Médio, em especial para os países que contestavam sua atuação na região, como Iraque, Afeganistão e Irã.

$4 \quad$ Devemos ter em conta que no momento que Nilson de Souza escreve a CELAC ainda não tinha sido criada, mas as bases do novo organismo já estavam sendo criadas, como a Cúpula da América Latina e Caribe para o Desenvolvimento e Integração (CALC), criada em 2008 como iniciativa do Brasil no governo do presidente Lula da Silva. Isso reflete de forma geral, o contexto atual referente à integração regional.
} 
desafios que despontavam no cenário internacional. Neste sentido, a concertação política alcançada neste período conseguiu modificar os rumos que os processos de integração regional haviam experimentado desde suas origens, deixando de privilegiar os fatores econômico-comerciais e passando a focar nos fatores político-sociais destes processos.

No entendimento dos novos governos da região, havia que ter uma articulação de alianças políticas para aproveitar as transformações no sistema internacional dos últimos anos que deixaram evidentes a existência de um mundo cada vez mais multipolar, com o surgimento de novos atores e novos temas, onde o papel dos Estados Unidos e suas políticas unilaterais não estavam mais figurando como único e hegemônico centro de poder. Neste contexto, a Declaração de Salvador da Bahia da I Cúpula da CALC afirmou o seguinte:

importancia de que el diálogo y la cooperación entre los países latinoamericanos y caribeños generen resultados tangibles y beneficios mutuos, acordes con las altas aspiraciones de desarrollo y prosperidad de sus respectivas sociedades, teniendo como base el intercambio de experiencias y de conocimientos y con fundamento en el patrimonio acumulado por las instituciones regionales existentes. (SERBIN, 2008, p. 60).

Dessa reunião foram elaborados diversos comunicados especiais ${ }^{5}$; dentre estes um pedido ao fim do bloqueio estadunidense a Cuba. Esta última declaração merece destaque, sendo que a articulação política tratou de reincorporar estrategicamente o Estado cubano ao sistema interamericano, condenando o bloqueio estadunidense ao país desde o ano de 1962, assim como convidando Cuba a participar como membro pleno da cúpula, o que demonstra a importância simbólica da ilha e de suas ideias para a integração regional. Esse fato demonstra o que discutimos anteriormente com relação à busca por uma maior autonomia e soberania, assim como a revitalização da identidade latino-americana compartilhada nos espaços de diálogo e concertação política.

Em novembro de 2009, os Ministros das Relações Exteriores de todos os países latinoamericanos se reuniram em Montego Bay, Jamaica, para estabelecer o Plano de Ação da CALC com o objetivo de colocar em prática os compromissos que os chefes de Estado e de Governo haviam assumido na Cúpula de Salvador. Nesta reunião, os chanceleres acordaram

5 Com relação à soberania argentina sobre as Ilhas Malvinas; Apoio a Bolívia diante da ameaça dos Estados Unidos em eliminar os benefícios da Lei de Promoção Comercial Andina e a Erradicação de Drogas; Desbloqueio dos EUA a Cuba. 
diversas áreas de ação, que vão desde o político e o econômico até temas específicos como crise financeira internacional, mudanças climáticas e desastres naturais.

No ano seguinte, a II Cúpula da CALC foi conjunta com a XXI Cúpula do Grupo do Rio. Essa reunião foi o espaço privilegiado para discutir a criação da Comunidade de Estados Latino-Americanos e Caribenhos (CELAC).

\section{A CÚPULA DE CARACAS}

Em dezembro de 2011, ocorreu em Caracas a XXII Cúpula do Grupo do Rio e a III CALC. Nesse encontro é fundada oficialmente a nova organização, assim como o seu plano de ação com as temáticas a discutir e aprofundar em encontros posteriores.

Além da Declaração de Caracas, a cúpula adotou vinte declarações e comunicados especiais sobre diversos temas; ademais, estabeleceu que a CELAC reunisse todos os 33 países da região e herdará o patrimônio de concertação política do Grupo do Rio e a agenda de integração e desenvolvimento da CALC que a partir desse momento deixaram de existir e passaram seu legado de acordos e consensos à nova organização. Segundo o Ministério das Relações Exteriores do Brasil (2009), a convergência da CALC e do Grupo do Rio ocorreria de forma gradual. Ambos os mecanismos "manterão suas agendas e métodos de trabalho até a conclusão do processo de constituição da CELAC pela adoção de seu documento constitutivo (BRASIL, MRE, 2009).

O Plano de Ação da CELAC, aprovado na cúpula de 2011, é o documento que contêm os dez grandes temas de discussão da nova organização e propõe mais de cinquenta ações para tais temas. As dez áreas temáticas se dividem em:

Crise financeira internacional e a nova arquitetura financeira; complementaridade e cooperação entre os mecanismos regionais e sub-regionais de integração; Energia; Infraestrutura para a integração física do transporte, as telecomunicações e a integração fronteiriça; Desenvolvimento social e erradicação da fome e a pobreza; Meio ambiente; Assistência humanitária; Proteção ao migrante; Cultura; Tecnologia da Informação e comunicações (CELAC, PLANO DE AÇÃO, 2011, p. 1).

Na mesma cúpula, foi aprovado o documento de procedimentos para o funcionamento da estrutura orgânica da nova entidade. A CELAC está estruturada em seis níveis de decisão 
para que possa funcionar de acordo com seus objetivos propostos. Os seis órgãos são: Cúpula de Chefas e Chefas de Estado e de Governo; Reunião de Ministras e Ministros de Relações Exteriores, Presidência Pró-Tempore, Reunião de Coordenadores Nacionais e a Troika.

Vale a pena ressaltar a Troika Ampliada que é um mecanismo herdado do Grupo do Rio e exerce a presidência da CELAC. Em 2014 a presidência pró-tempore é exercida por Costa Rica acompanhada de Cuba que exerceu no período anterior e Equador que exercerá a presidência em 2015. A primeira reunião da Troika aconteceu em 2012 em Santiago do Chile, quando os três países (Venezuela, Chile e Cuba) acordaram cinco temas referenciais para a cúpula de 2013: "energia, ciência e tecnologia, infraestrutura, finanças e desenvolvimento social." (CELAC, PLANO DE AÇÃO, 2011, p. 4).

As decisões do organismo são adotadas "por consenso em todas as instâncias" (CELAC, PLANO DE AÇÃO, 2011, p.05). As mesmas se manifestarão através de declarações, decisões, comunicados conjuntos e especiais, resoluções ou outro instrumento acordado pelos países, sendo que "todas têm caráter de acordos políticos e constituem mandatos.” (idem, p. 5). Segundo Aravena (2012):

Este fue uno de los temas que generó un mayor debate en la Cumbre de Caracas, al menos dos gobiernos señalaron que el mecanismo de decisión por consenso podía lentificar el proceso y a la vez bloquearlo, por lo que buscaron introducir mecanismos que pudiesen establecer alguna forma de votación en los procesos decisorios. Sin embargo, la mayoría señaló que el consenso era la forma más efectiva en un proceso como el de la CELAC (ARAVENA, 2012, p. 85).

Por sua parte, autores como Bernal Meza apontam que a CELAC foi um projeto do presidente Chávez, já que ele pessoalmente procurou que sejam uma ponte entre a concepção "sul-americana" (que dominou a visão brasileira até 2008) e o conceito de latino-americano. Foi também a presença no discurso de Chávez e da ALBA no que se refere ao reconhecimento das etnias dos povos originários e das culturas que foram subordinadas historicamente. (BERNAL-MEZA, 2012). No que tange a Troika, o autor afirma que esse mecanismo lhe dá um perfil de continuidade as linhas de gestão da política regional.

O vínculo da comunidade latino-americana e caribenha com as outras regiões e organismos internacionais são assumidos pela CELAC através do diálogo político e diplomático em fóruns, encontros, cúpulas e reuniões especializadas da comunidade com os demais países, além da herança dos diálogos do Grupo do Rio com a União Europeia, assim 
como a interlocução em espaços multilaterais como a ONU. Nesse pouco tempo de existência, a entidade já se reuniu com países de grande peso no cenário internacional como Rússia e em especial a China ${ }^{6}$, o que mostra uma mirada estratégica da região em um mundo em constante transformação.

\section{CELAC VS OEA: PARALELAS OU EM DISPUTA?}

A criação da CELAC leva a crer que em algum momento a nova instituição confrontará a atuação da tradicional Organização dos Estados Americanos (OEA), criada em 1948, em um contexto de pós-II Segunda Guerra Mundial, impulsionada e influenciada até os dias atuais pelo governo estadunidense. A organização que abarca todos os Estados americanos é considerada o principal fórum das relações regionais dos últimos 50 anos (SEITENFUS, 2008) e tem como objetivos o "[...] compromisso com a democracia, fortalecimento dos direitos humanos e a garantia da paz e da segurança no continente." (Carta da OEA, p. 2).

A organização americana é historicamente alvo de críticas de vários governos latinoamericanos; algumas dessas críticas dizem respeito a pouca atuação do organismo em temas de interesse regional e ao apoio aos Estados Unidos na invasão a Santo Domingo e nos golpes militares no Brasil (1964), no Chile (1973), Uruguai (1974) e Argentina (1976), todos dentro da proposta de segurança coletiva e com o total apoio do governo norte-americano (FICO, 2008). Nos anos de 1960, a postura da OEA de expulsar e autorizar um bloqueio a Cuba em pleno auge da "Crise dos Mísseis" também demonstrou que a organização atendia aos interesses de política externa estadunidense.

Na questão das Ilhas Malvinas ${ }^{7}$ entre Argentina e Inglaterra, houve uma clara falta de posição sobre o conflito por parte da OEA. Nesse sentido, Fagundes (FAGUNDES, 2010) vai afirmar que a proposta do multilateralismo que inspirou a fundação da OEA ficou quase sempre em segundo plano em relação às posições políticas e à vontade de cooperação do

\footnotetext{
6 Em 26 de julho se realizou um encontro entre a CELAC e a China em Brasília, Brasil. A cúpula lançou oficialmente um fórum de chanceleres entre China e os países latino-americanos que conformam a CELAC. O objetivo principal é aprofundar a relação por meio da maior cooperação entre as duas regiões. $<$ http://celac.cubaminrex.cu/es/articulos/celebraran-cumbre-china-celac-en-julio-proximo-en-brasilia >. Acesso em: 12 de maio. 2016

7 Território disputado historicamente entre Argentina e Inglaterra. O Estado argentino reivindica a soberania desse território, apesar de ter perdido a guerra travada com a Inglaterra pela soberania das ilhas em 1982. Os britânicos afirmam que o território é inglês pelo respeito ao direito internacional e princípio da autodeterminação dos povos, sendo que a maior parte da população local que vive quer continuar pertencendo à jurisdição inglesa.
} 
governo dos EUA, que durante a Guerra das Malvinas também esteve ao lado dos ingleses, num claro desrespeito aos acordos continentais, como o Tratado Interamericano de Assistência Recíproca (TIAR).

Iniciativas recentes de integração regional já têm se posicionado a favor de um diálogo mais sério entre os dois países. A CALC, em sua declaração final, afirmou que no âmbito da OEA, a questão das Malvinas é um tema de interesse hemisférico, indicando que a Argentina e Inglaterra retomem, o quanto antes, as negociações sobre a disputa de soberania sobre as Ilhas Malvinas, Geórgia do Sul, Sandwich do Sul e os espaços marítimos circundantes, visando encontrar uma solução pacífica a esta prolongada controvérsia (CALC, 2008).

Outro conflito recente que a OEA não conseguiu resolver foi a crise diplomática entre Colômbia e a Venezuela em 2008, quando o governo colombiano enviou tropas do exército para acabar com um acampamento das Forças Revolucionárias da Colômbia (FARC) em território equatoriano e se tornou mais crítico no ano seguinte, quando a Colômbia autorizou a implantação de mais bases militares estadunidenses em seu território.

A problemática foi levada ao âmbito da OEA, onde não teve sucesso esperado pela comunidade internacional. No entanto, dias depois, na XX cúpula do Grupo do Rio, em Santo Domingo, os governos latino-americanos presentes, em sua declaração final, rejeitaram a violação a integridade territorial do Equador e ratificaram o princípio da não ocupação militar direta ou indireta, qualquer que seja o motivo, ainda que de maneira temporária. (GRUPO DO RIO, 2008, p. 3). Também mostraram sua satisfação pelo pedido de desculpas do então presidente Álvaro Uribe Vélez por seu compromisso de que estes fatos não se repitam abaixo nenhuma circunstância. Por fim, reiteraram seu compromisso com a convivência pacífica na região e a iniciativa de combater a ameaça da segurança de todos os Estados de organizações criminais (idem, p. 3).

Sobre a incapacidade histórica da OEA em resolver conflitos dessa natureza e a efetividade que tem tido outros mecanismos de concertação política regional como a CALC e o Grupo do Rio, o autor Ricardo Seitenfus (2008) coloca que a partir dos anos 80, quando a região vivia um ambiente difícil na área econômica e política:

[...] surgiram questões tais como os conflitos na América Central, o narcotráfico, a Guerra das Malvinas, o crescimento da dívida externa e a crise econômica, que transforma o período na chamada década perdida na América Latina. As tentativas para resolver tais dilemas transcorrem longe do alcance da OEA. Novos fóruns criados como o Grupo do Rio, o de Contadora, o de apoio a Contadora, o SELA, as 
integrações econômicas regionais e as negociações bilaterais, tentando contornar a possível falência financeira dos Estados latino-americanos. A OEA somente foi notada em razão de sua cabal incapacidade para enfrentar estas questões (SEITENFUS, 2008, p. 275).

Nesse sentido, Senteifus complementa que há duas alternativas para que a OEA continue cumprindo seu papel: ou encontra novas funções e objetivos ou desaparecerá. Diante da falta e posicionamento em diversos conflitos regionais e do histórico de pouca capacidade da OEA em dar soluções concretas a problemáticas latino-americanas, as novas iniciativas de integração seriam uma alternativa mais eficiente e adequada de acordo com o novo cenário internacional (SENTEIFUS, 2008, p. 277).

O fato da OEA não ter conseguido dar soluções às disputas entre os países latinoamericanos e destes com outros Estados dá maior espaço de atuação a CELAC como uma organização que, além de se propor a intermediar e dar respostas aos problemas regionais almeja construir uma identidade compartilhada entre os diversos atores regionais, abrindo espaço para novos processos de integração latino-americanos, desta maneira, a CELAC traz para sua jurisdição assuntos como a concertação política que antes eram parte do rol de atuação da OEA.

No entanto, para saber se a CELAC virá a substituir ou não a OEA dependerá muito da atuação da nova organização, o que pode ser analisado com mais clareza no futuro. A continuação passará a analisar outro assunto que constitui um desafio que se remete a natureza jurídica dos blocos regionais de integração.

\section{CONSIDERAÇÕES FINAIS}

Ao longo desse artigo, vimos que a CELAC possui antecedentes que fazem dela uma organização com grande responsabilidade histórica, por herdar as lutas contidas durante os governos autoritários, como o antigo Grupo de Contadora e o Grupo do Rio, ambos de vital importância para a conformação dos objetivos e dos valores que devem reger a nova organização. Identificamos ao longo da discussão três grandes desafios que são fundamentais para que a CELAC possa desenvolver suas funções de acordo com seus objetivos. O primeiro seria o papel da Organização dos Estados Americanos (OEA) diante da criação da CELAC. Neste ponto, vimos que há duras críticas a atuação da tradicional organização continental, com relação a vários conflitos na região. Chega-se à conclusão de que as duas organizações por mais que também seja espaço de diálogo em concertação política, possuem características 
bastante distintas e a resposta para saber se a CELAC substituirá ou não a OEA dependerá da atuação da nova organização, o que pode ser visto com mais clareza em análises futuras. Um segundo desafio é a tomada de decisão dentro do novo organismo, sendo que este resolve suas discussões na base do consenso, o que torna a CELAC mais flexível e sem as características de uma organização internacional tradicional.

Podemos identificar que essa característica ajuda a nova organização a dialogar com os diversos mecanismos sub-regionais de integração, com visões e objetivos diferenciados sobre os temas da arena regional e internacional. Por último, abordamos o desafio de criar uma verdadeira comunidade latino-americana e que a CELAC seja uma representante legitima dessa comunidade nos fóruns regionais e internacionais. Para isso, há que se criar uma identidade latino-americana e caribenha, sendo este identificado como o principal desafio da nova organização.

Assim, o que se objetivou com esse artigo é entender o surgimento da CELAC, através de um histórico de projetos e instituições de cooperação criadas em diversos momentos da história latino-americana, comprovando a argumentação de que existe um histórico de concertação e diálogo político no continente e que deu bases para criação de tal organismo. O desejo é que a discussão realizada nesse artigo tenha contribuído para o entendimento sobre a integração latino-americana atual, tema ainda pouco discutido e aprofundado no ambiente acadêmico brasileiro.

\section{REFERENCIAS}

ALTMANN Borbón, Josette y ROJAS Aravena, Francisco. Multilateralismo e Integración en América Latina y el Caribe. En: ALTMANN Borbón, Josette y ROJAS. Aravena, Francisco (editores). Las paradojas de la Integración en América Latina y el Caribe. Fundación Carolina/Siglo XXI Editores. Madrid, 2008.

, Josette. Dossiê: Grupo do Rio. São José: Fundação Carolina, 2007.

ARAUJO, Heloisa Vilhena de. O Grupo do Rio e a globalização: grupo de reflexão de alto nível. Brasília: Fundação Alexandre Gusmão, 2005.

BANDEIRA, Luiz A. Muniz. Conflito e Integração na América do Sul - Brasil, Argentina e Estados Unidos: da Tríplice Aliança ao MERCOSUL (1870-2003.). Rio de Janeiro: Revan, 2003, p. 124-152.

BERNAL-MEZA, Raúl. América Latina en el Mundo: El pensamiento latinoamericano y la teoría de relaciones internacionales. Buenos Aires: Editora Nuevo Hacer, 2005.

BUENO, Clodoaldo. Pan-Americanismo e Projetos de Integração: temas recorrentes na 
história das relações hemisféricas (1826-2003).Política Externa, São Paulo, v. 13, n. 1, 2004.

CERVO, Amado. Relações Internacionais da América Latina: velhos e novos paradigmas. Brasília: IBRI, 2008.

DULCI, Tereza Maria Spyer. As Conferências Pan-Americanas: identidades, união aduaneira e arbitragem (1889 a 1928). São Paulo: Tese de Mestrado, Departamento de História, FFLCH, USP, 2008.

HERZ, Mônica; HOFFMANN, Andréa Ribeiro. Organizações Internacionais: história e práticas. $1^{\mathrm{a}} \mathrm{ed}$. Rio de Janeiro: Campus Elsevier, 2004.

MONIZ BANDEIRA, Luiz Alberto. Brasil, Argentina e Estados Unidos. Conflito $e$ Integração na América do Sul (Da Tríplice Aliança ao MERCOSUL), 1870-2007. Rio de Janeiro: Civilização Brasileira, 2010.

ROJAS, Aravena Francisco. La Celac y la integración latinoamericana y caribeña: Principales claves y desafios. Chile: Revista Nueva Sociedad, n. 240, 2012.

Multilateralismo e integración en América Latina y el Caribe. San José: FLACSO-Secretaria General, 2007.

SILVA, Luisa Maria Nunes de Moura e. Relações internacionais do Brasil e integração Latino-americana. São Paulo: Fontes Novas, 2008.

SOUZA, Nilson Araujo. A América Latina: as ondas da integração. Revista OIKOS. Rio de Janeiro, v. 11. n. 1, 2012.

Recebido em 09/05/2016.

Aceito em 11/03/2017.

Publicado em 21/09/2017.

DOI: 10.11606/issn.1676-6288.prolam.2016.115232 